\section{KẾT LUẬN}

- Tuổi trung bình của đối tượng nghiên cứu là $37,2 \pm 15,8$ tuổi. Tỉ lệ nam/ nữ là $1,7 / 1$.

- Bệnh nhân ngộ độc cấp có toan lactic có triệu chứng lâm sàng và cận lâm sàng phức tạp. Dấu hiệu lâm sàng thường gặp là buôn nôn và nôn $(61,4 \%)$, mạch nhanh $(43,3 \%)$, đau đâu $(33,8 \%)$, rối loạn ý thức $(32,2 \%)$, tụt huyết áp $(25,9 \%)$, suy hố hấp (27,5\%). Dấu hiệu cận lâm sàng: tăng bạch câu $(40,9 \%)$, thiếu máu $(34,6 \%)$, suy thận cấp $(14,1 \%)$, tăng glucose $(29,1 \%)$, hạ natri $(17,3 \%)$ và hạ kali $(26,8 \%)$,

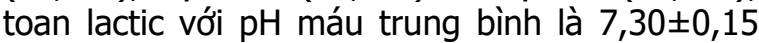
và $18,9 \%$ có toan chuyển hóa nặng.

\section{TÀI LIÊU THAM KHẢO}

1. Gummin DD, Mowry JB, Spyker DA, et al. 2017 Annual Report of the American Association of Poison Control Centers' National Poison Data System (NPDS): 35th Annual Report. Clin Toxicol (Phila). 2018;56(12):1213-1415.

2. Kraut JA, Madias NE. Lactic Acidosis. New England Journal of Medicine. 2014;371(24):2309-2319.
3. Haas SA, Lange T, Saugel B, et al. Severe hyperlactatemia, lactate clearance and mortality in unselected critically ill patients. Intensive Care Med. 2016;42(2):202-210.

4. Nguyễn Thị Dụ. Định hướng chung chẩn đoán và xử trí ngộ độc cấp, Tư vấn chẩn đoán và xử trí nhanh ngộ độc câp. Nhà xuất bản $Y$ học Hà Nội. 2004; 9-22.

5. Suetrong B, Walley KR. Lactic Acidosis in Sepsis: It's Not All Anaerobic: Implications for Diagnosis and Management. Chest. 2016; 149(1): 252-261.

6. Gholamzera Massoumi, Saberi K, EizadiMood N, et al. Methanol poisoning in Iran, from 2000 to 2009. Drug and Chemical Toxicology. 2012;35(3):330-333.

7. Nguyến Đàm Chính, Hà Trân Hưng. Đặc điểm lâm sàng, cận lâm sàng ngộ độc cấp Methanol. Thây Thuốc Việt Nam, 2019.

8. Sanaei-Zadeh $\mathbf{H}$, Kazemi Esfeh $\mathbf{S}$, Zamani $\mathbf{N}$, et al. Hyperglycemia Is a Strong Prognostic Factor of Lethality in Methanol Poisoning. J Med Toxicol. 2011;7(3):189-194.

9. Van Dijken GD, Blom RE, Hene RJ, et al. High incidence of mild hyponatremia in females using ecstasy at a rave party. Nephrol Dial Transplant. 2013; 28(9):2277-83.

\title{
LỢI ÍCH VÀ KHÓ KHĂN CỦA HOẠT ĐộNG THAY THẾ THUỐC GENERIC TẠI NHÀ THUỐC TRONG CộNG ĐỒNG Ở HÀ NộI
}

\section{TÓM TẮT}

Mục tiêu: Nghiên cứu khám phá có mục tiêu là đánh giá lợi ích và khó khăn của việc thay thế thuốc generic tại các nhà thuốc cộng đồng Hà Nội. Phương pháp nghiên cứu: Nghiên cứu cắt ngang sử dụng bộ câu hỏi tự điền. Kỹ thuật chọn mẫu thuận tiện được sử dụng trong nghiên cứu này trong đó bộ câu hỏi thu thập dữ liệu được phân phối đến người bán lẻ thuốc đang hành nghề tại 5 quận Hà Nội. Kết quả: Tổng số 203 người bán lẻ thuốc được phỏng vấn, hầu hết là nữ giới $(89,9 \%)$. Lợi ích được ghi nhận nhiều nhất của việc thay thế thuốc generic là giá rẻ hơn cho khách hàng $(91,1 \%)$. Hai rào cản chính là có thể xuất hiện nhà thuốc độc quyên một số thuốc generic $(63,1 \%)$ và tác động đến mối quan hệ với người bệnh khi thuốc generic không hiệu quả $(53,2 \%)$. Kết luận: Hiệu quả và kinh tế là những vấn đề được quan tẩm; tuy nhiên người bán lẻ đều thừa nhận những lợi ích kinh tế đối với hệ thống chăm sóc sức khoẻ.

Tư khoá: thuốc generic, nhà thuốc, Hà Nội

\section{*Trường Đại học Dược Hà Nội}

Chịu trách nhiệm chính: Lê Thu Thuỷ

Email: lethuy274@gmail.com

Ngày nhận bài: 19.01.2021

Ngày phản biên khoa học: 15.3.2021

Ngày duyệt bài: 23.3.2021
Lê Thu Thủy*, Ninh Thế Vũ *

\section{SUMMARY \\ FACILITATORS AND BARRIERS OF SUBSITUTING GENERIC DRUGS IN HANOI COMMUNITY PHARMACIES}

Objective: This objective of this exploratory study was to examine the facilitators and barriers of substituting generic drugs in Hanoi community pharmacies. Methods: This study was a crosssectional observational study employing a selfadministered questionnaire. A convenience sampling technique was implemented in this study in which the data collection form was distributed among practicing pharmacists at 5 districts. Results: A total of 203 community pharmacists were interviewed, most of them were females (89.9\%). The main facilitator affecting pharmacists' supply of generic medicines was cheaper cost to the customer $(91.1 \%)$. The main two barriers were possible emergency of single colour pharmacies $(63.1 \%)$ and impacting of relationship with patient when generic medicine is not effective $(53.2 \%)$. Conclusions: Concerns were raised regarding to effectivenes, business; however, most of the pharmacists acknowledged the economic benefits to the heath care system.

Keywords: generic drugs, pharmacy, Hanoi

\section{I. ĐĂT VẤN ĐỀ}

Một chiến lược quan trọng giúp kiểm soát chi phí chăm sóc sức khoẻ là thúc đẩy sử dụng các 
thuốc generic có giá phù hợp, an toàn và hiêu quả thay vì sử dụng các thuốc biệt dược gốc đắt tiền. Việc sử dụng thuốc generic giúp tiết kiệm đáng kể chi phí và tăng khả năng tiếp cận với thuốc cho người bệnh. Tại nhiều quốc gia, dược sĩ được phép thay thế thuốc generic và đây được coi là một chiến lược giúp tiết kiệm chi phí cho người bệnh, hệ thống chăm sóc sức khoẻ và xã hội nói chung và quỹ Bảo hiểm xã hội. Việt Nam cũ̃ng có những chính sách, chiến lược nhằm phát triển và tăng cường sử dụng thuốc generic trong điều trị [2]. Pháp luật Việt Nam cũng cho phép dược sĩ được phép thay thế thuốc cùng hoạt chẩt, đường dùng và liều dùng khi có sự đồng ý của người mua và dước sĩ phải chiu trách nhiêm về viêc thay đổi thuốc [1]. Việc thay thế thuốc bao gồm việc thay thế thuốc generic. Thay thế thuốc generic giúp mang lại những lợi ích cho người bênh và nhà thuốc như giảm chi phí thuốc, tăng lợi nhuân... Bên cạnh những lợi ích thì một số nghiên cứu cũng chỉ ra những rào cản như dược sĩ phải sử dụng thêm thời gian để giải thích cho khách hàng, xuất hiện nhà thuốc độc quyền thuốc generic... [5],[8]. Nhâan thức về lợi ích và khó khăn sẽ ảnh hưởng đến thực hành thay thế thuốc generic của dược sĩ. Tại Việt Nam, theo hiểu biết của chúng tôi, hiện nay chưa có nghiên cứu nào về nhận thức của người bán lẻ về lợi ích và khó khăn của việc thay thế thuốc generic. Chính vì vậy, câu hỏi đặt ra là có những thuận lợi, khó khăn gì khi thay thế thuốc generic tại các nhà thuốc trong cộng đồng tại Việt Nam. Do đó, chúng tôi tiến hành nghiên cứu này nhằm tìm hiểu những thuận lợi và khó khăn của hoat động thay thế thuốc generic ở các nhà thuốc cộng đồng tại Hà Nội.

\section{II. ĐỐI TƯƠ'NG VÀ PHƯƠNG PHÁP NGHIÊN CỨU}

2.1. Đối tượng nghiên cứu. Người bán lẻ thuốc đang hành nghề tại các nhà thuốc ở Hà Nội. Người bán lẻ thuốc không đồng ý tham gia nghiên cứu hoặc chưa tốt nghiệp một trường đào tạo về Dược sẽ được loại trừ ra khỏi nghiên cứu.

2.2. Phương pháp nghiên cứu. Nghiên cứu mô tả cắt ngang sử dụng bộ câu hỏi tự điền được thực hiện năm 2019. Bộ cẩu hỏi được thiết kế dựa trên một số nghiên cứu trước đây [3], [4], [5], [6], [8],[9]. Sử dụng phương pháp chọn mâ̂u thuận tiện, tại mỗi nhà thuốc sẽ mời một người người bán lẻ đáp ứng tiêu chuẩn lựa chọn và loại trừ tham gia khảo sát. Tiến hành nghiên cứu thử nghiệm để điều chỉnh bộ câu hỏi trước khi tiến hành nghiên cứu chính thức. Sử dung phần mềm R3.5.1. để phân tích dữ liệu. Phương pháp thống kê mô tả được sử dụng để phân tích dữ liệu. Biến phân loại số liệu trình bày là tân suất (tỉ lệ), biến liên tục trình bày số liệu là trung bình (SD) với phân bố chuẩn và trung vị (tứ phân vị) với phân bố không chuẩn.

\section{KẾT QUẢ NGHIÊN CỨU}

3.1. Thông tin chung về người bán lẻ thuốc tham gia nghiên cứu

Đăc điểm chung của đối tượng tham gia nghiên cứu được mô tả trong bảng 1 .

Bảng 1. Thông tin chung về người bán lẻ thuốc tham gia khảo sát

\begin{tabular}{|c|c|}
\hline Nội dung & Giá trị \\
\hline $\begin{array}{ll}\text { Giới tính, n (\%): } & \text { Nam } \\
\text { Nữ }\end{array}$ & $\begin{array}{c}20(10,1) \\
179(89,9)\end{array}$ \\
\hline Tuổi, trung vị (tứ phân vị) & $28(24-32)$ \\
\hline Trình độ, n (\%) & \\
\hline Đại học dược & $60(30,3)$ \\
\hline Cao đẳng dược & $91(46,0)$ \\
\hline Trung cấp dược & $47(23,7)$ \\
\hline Kinh nghiệm làm việc, $\mathrm{n}(\%)$ & \\
\hline Dưới 1 năm & $35(19,2)$ \\
\hline Từ 1 đến 3 năm & $66(36,3)$ \\
\hline Từ 3 đến 5 năm & $28(15,4)$ \\
\hline Từ 5 đến 10 năm & $38(20,9)$ \\
\hline Trên 10 năm & $15(8,2)$ \\
\hline Nguồn cung cấp kiến thức, $\mathrm{n}(\%)$ & \\
\hline Trường đại học, cao đắng & $125(62,8)$ \\
\hline Tham gia hội thảo & $82(41,2)$ \\
\hline Tài liệu chuyên môn, sách & $109(54,8)$ \\
\hline Mạng/ internet & $98(49,2)$ \\
\hline Tờ thông tin thuốc & $86(43,2)$ \\
\hline Người giới thiệu thuốc & $80(40,2)$ \\
\hline Đồng nghiêp, chủ nhà thuốc & $82(41,2)$ \\
\hline
\end{tabular}

Nghiên cứu phát ra 400 phiếu, 203 phiếu được đưa vào phân tích. Đối tượng tham gia nghiên cứu có $89,9 \%$ là nữ giới và độ tuổi có trung vị là 28. Người bán lẻ thuốc tham gia trả lời bao gồm nhiều trình độ khác nhau và khá tương đồng giữa các nhóm đối tượng đại học, cao đẳng và trung cấp. Người tham gia phỏng vấn có từ 1 đến 3 năm kinh nghiệm $(36,3 \%)$. Nguồn kiến thức chủ yếu của người bán lẻ về thuốc generic đến từ trường học, tài liệu chuyên môn/ sách và mạng/ internet (tỷ lệ tương ứng là $62,8 \% ; 54,8 \% ; 49,2 \%)$.

3.2. Lợi ích của hoạt động thay thế thuốc generic.

Lợi ích của việc thay thế thuốc generic ở nhà thuốc cộng đồng được thể hiện trong bảng 2.

Bảng 2. Lợi ích của hoạt động thay thế thuốc generic

\begin{tabular}{|c|c|c|}
\hline Lợi ích & $\begin{array}{c}\text { Số } \\
\text { lượng }\end{array}$ & $\begin{array}{c}\text { Tỷ lệ } \\
(\%)\end{array}$ \\
\hline
\end{tabular}




\begin{tabular}{|c|c|c|}
\hline Tiết kiệm chi phí cho người bệnh & 185 & 91,1 \\
\hline $\begin{array}{c}\text { Sữ dụng ít tiền hơn trong mua } \\
\text { săm thuốc tồn trữ }\end{array}$ & 127 & 62,6 \\
\hline $\begin{array}{c}\text { Nâng cao tính chư động và vị } \\
\text { thế của dược sĩ }\end{array}$ & 111 & 54,7 \\
\hline $\begin{array}{c}\text { Có được lợi nhuận lớn hơn từ } \\
\text { thuốc generic }\end{array}$ & 103 & 50,7 \\
\hline $\begin{array}{c}\text { Lời mời mua hàng hấp dẫn hơn } \\
\text { tữ các nhà bán buôn }\end{array}$ & 29 & 14,3 \\
\hline
\end{tabular}

Có $91,1 \%$ người bán lẻ cho rằng thay thể thuốc generic giúp tiết kiệm chi phí cho người bệnh. Những vấn đề liên quan đến chi phí đầu tư và lợi nhuận cũng được ghi nhận. 62,6\% người bán lé cho rằng thay thế thuốc generic giúp sử dụng ít tiền hơn trong mua sắm thuốc tôn trữ và $50,7 \%$ người bán lẻ cho rằng giúp đem lại lợi nhuận lớn hơn từ thuốc generic. Ngoài ra, trên $50 \%$ người bán lẻ còn cho rằng việc thay thế thuốc generic còn giúp nâng cao tính chủ động và vị thế của dược sĩ.

3.3. Khó khăn của hoạt động thay thế thuốc generic. Một số khó khăn có thể gặp khi thực hiện thay thế thuốc generic tại nhà thuốc trong cộng đồng được trình bày ở bảng 3 .

Bảng 3. Khó khăn của hoạt động thay thế thuốc generic

\begin{tabular}{|c|c|c|}
\hline Khó khăn & $\begin{array}{c}\text { Số } \\
\text { lươong }\end{array}$ & $\begin{array}{l}\text { Tỷ lệ } \\
\text { (\%) }\end{array}$ \\
\hline $\begin{array}{l}\text { Có thế xuất hiện nhà thuốc độc } \\
\text { quyền một số thuốc generic }\end{array}$ & 128 & 63,1 \\
\hline $\begin{array}{c}\text { Tác động đến mối quan hệ với } \\
\text { người bệh khi thuốc generic } \\
\text { không hiệu quả }\end{array}$ & 108 & 53,2 \\
\hline $\begin{array}{c}\text { Cần dự trù nhiều thuốc (cả thuốc } \\
\text { generic và biệt dược gốc) nhằm } \\
\text { đáp ứng sự lựa chọn của khách } \\
\text { hàng }\end{array}$ & 105 & 51,7 \\
\hline $\begin{array}{l}\text { Dược sĩ phải sử dụng thêm thời } \\
\text { gian để giải thích sự thay đổi đối } \\
\text { với khách hàng }\end{array}$ & 98 & 48,3 \\
\hline $\begin{array}{l}\text { Bác sĩ không biết loại thuốc cụ thê } \\
\text { mà người bệnh sử dụng }\end{array}$ & 91 & 44,8 \\
\hline $\begin{array}{c}\text { Người bệnh có thế từ chối vì có } \\
\text { thể nguy cơ cao hơn gặp phản } \\
\text { ứng có hại }\end{array}$ & 77 & 37,9 \\
\hline $\begin{array}{l}\text { Nguy cơ gặp các sai sót liên quan } \\
\text { đến thuốc như sử dụng thuốc } \\
\text { trùng lặp hoặc các sai sót khác }\end{array}$ & 69 & 33,4 \\
\hline $\begin{array}{l}\text { Trách nhiệm không rõ ràng khi } \\
\text { người bệnh gặp phản ứng có hại } \\
\text { của thuốc }\end{array}$ & 65 & 32,0 \\
\hline
\end{tabular}

Khó khăn được ghi nhận nhiều nhất của hoạt động thay thế thuốc generic là có thể làm xuất hiện các nhà thuốc độc quyền (tỉ lệ 63,1\%). Tiếp theo, $53,2 \%$ người bán lẻ cho rằng hoạt động này sẽ ảnh hưởng tiêu cực đến mối quan hệ của người bệnh khi sử dụng thuốc generic mà không hiệu quả. Và $51,7 \%$ người bán lẻ cho rằng sẽ cân dự trù nhiều thuốc (cả thuốc generic và biệt dược gốc) nhằm đáp ứng sự lựa chọn của khách hàng.

\section{BÀN LUÂN}

Hoạt động thay thế thuốc generic được ghi nhận cho thấy giúp mang lại cả những lợi ích nhưng đồng thời cũng có những khó khăn đối với nhà thuốc trong cộng đồng.

Nhìn chung, lợi ích của việc thay thế thuốc generic đối với nhà thuốc cộng đồng chủ yếu liên quan đến giá cả và lợi nhuận. Thuốc generic thường có giá rẻ hơn biêt dược gốc do tốn ít chi phí nghiên cứu, sản xuất hớn. Phần lớn người bán lẻ $(91,11 \%)$ thay thế thuốc generic giúp tiết kiệm chi phí cho người bệnh. Kết quả này tương tự với nghiên cứu tại Cộng hoà Séc $(93,3 \%)$ [8], New Zealand $(82,5 \%)[5]$, Quatar $(82,4 \%)$ và Palestine (79,8\%)[9]. Một nghiên cứu của Cameron $A$. và cộng sự thực hiện trên 17 nước đã cho thấy với các nước đang phát triển, sử dụng thuốc generic giúp giảm chi phi thuốc trung bình là $65 \%$, (dao động từ 9-89\%). Ngoài ra, phần lớn người bán lẻ cho rằng việc bán và thay thế thuốc generic sẽ giúp nâng cao tính chủ động và vị thế của dược sĩ. Kết quả này cũng tương tự với kết quả nghiên cứu tại Cộng hoà Séc $(67,3 \%$ cho rằng giúp nâng cao vị thế của người bán lẻ)[8]. Tuy nhiên, người bán lẻ ý thức tại Việt Nam hay Séc đều ý thức được việc nâng cao địa vị và quyền ra quyết định của họ có thể mang lại một số hậu quả tiêu cực như trách nhiêm pháp lý đối với các phản ứng có hại của thuốc và việc cấp phát thuốc mất nhiêu thời gian hơn.

Hơn $50 \%$ người bán lẻ cho rằng thuốc generic có thể mang lại lợi nhuận cao hơn cho nhà thuốc. Kết quả này trái ngược với nghiên cứu tại New Zealand[5]. Tại New Zealand 67,6\% người bán lẻ cho rằng thuốc generic mang lại lợi nhuận ít hơn trên mối đơn vị thuốc do đó phải tăng số lượng bán để duy trì được lợi nhuận của nhà thuốc. Sự khác biệt này là do tại $\mathrm{New}$ Zealand thuốc generic thường được chính phủ trợ giá nên giá thấp, lợi nhuận ít.

Rào cản lớn nhất theo người bán lẻ ở nhà thuốc cộng đồng ở Hà Nội đó là có thể xuất hiện các nhà thuốc độc quyền một số thuốc $(63,1 \%)$. Kết quả này khác với kết quả một số nghiên cứu đã công bố trước đây. Khó khăn lớn nhất được ghi nhâan tại Séc [8] là nguy cơ sử dụng thuốc trùng lặp hoặc các sai sót khác liên quan đến 
thuốc do người bênh gây ra $(72,7 \%)$ còn tại New Zealand[5] là vấn đề phải thêm thời gian giải thích sự thay đổi đối với khách hàng (84\%). Tuy nhiên, đây cũng đều là các rào cản có tỉ lệ lựa chọn cao trong kết quả nghiên cứu của chúng tôi (trên 48\%). Khi người bán lẻ thay thế thuốc cho người bệnh thì sẽ phải dành thời gian để cung cấp thông tin. Tuy nhiên, tại Việt Nam và nhiều quốc gia trong đó có New Zealand chưa được hoàn trả cho thời gian giải thích sự thay đổi cho người bênh. Tai một số quốc gia như Đức, Mỹ và Anh đã sử dụng thành công biện pháp khuyến khích tài chính để tăng cường phân phối thuốc generic [7].

Thay thế thuốc generic sẽ ảnh hưởng đến mối quan hệ với người bệnh khi thuốc generic không hiệu quả cũng là một rào cản được ghi nhận (53,2\%). Nghiên cứu tại New Zealand [5] thì ghi nhận tî lệ này rất thấp $(1,3 \%)$. Điều này có thể là do tại Việt Nam hiện nay chỉ có một số hoạt chất thì quy định thuốc generic bắt buộc phải làm tương đương sinh học với thuốc biệt dược gốc còn hầu hết các thuốc generic hiện nay trên thị trường được sản xuất mà không đánh giá tương đương sinh nên hiệu quả thực tế trong quá trình sử dụng có thể khồng bằng thuốc biêt dước gốc. Còn tại New Zealand thì các thuốc phải được đánh giá bởi Medsafe và đánh giá tương đương sinh học là yêu câu cơ bản nếu muốn đưa ra thị trường. Do đó, các dược sĩ có niềm tin vào hiệu quả điều trị của thuốc generic cao.

Chỉ có $14,3 \%$ người bán lẻ cho rằng lời mời mua hàng hấp dẫn từ các nhà bán buôn là lợi ích của thay thế thuốc generic. Tỉ lệ thấp nhưng vẫn cao hơn nghiên cứu tại New Zealand $(1,0 \%)$ [5]. Ngoài ra, 44,8\% người bán lẻ cho rằng khó khăn là người kê đơn sẽ không biết về thuốc cụ thể mà người bênh sử dụng. Kết quả này tương tự với kết quả nghiên cứu tại Séc $(42,6 \%)$ [8].

Những vấn đề về an toàn trong sứ dụng cũng là rào cản khi thay thế thuốc generic. $32,0 \%$ người bán lẻ trong nghiên cứu của chúng tôi cho rằng trách nhiệm không rõ ràng khi người bệnh gặp phản ứng có hại. Nghiên cứu tại Séc $[8]$, tỉ lệ nhận thức về khó khăn này cao hơn $(49,6 \%$ người bán lẻ lo lắng về vấn đề này). Điều này có thể là do trong quy định GPP của Việt Nam đã quy định rõ là trong trường hợp thay thế thì người bán lẻ phải chịu trách nhiệm về việc thay đổi thuốc. Bên cạnh vấn đề gặp phải về phản ứng có hại thì nguy cơ về các sai sót liên quan đến thuốc như sử dụng thuốc trùng lặp cũng là vấn đề khó khăn. Tại Viêt Nam, người bán lẻ tại nhà thuốc trong cộng đồng không được tiếp cận với hồ sơ bệnh án của người bệnh vì vậy nếu không chú ý khai thác thông tin thì có thể dẫn đến những sai sót sử dụng thuốc này. Việc sử dụng thuốc trùng lặp có thể tác động tiêu cực nghiêm trọng dến sức khẻo người bệnh. Những sợ hãi và lo lắng của người bán lẻ có thể được thúc đẩy bởi trải nghiệm hàng ngày của họ với đơn thuốc trùng lăp. Ngoài ra, 37,9\% người bán lẻ cho rằng khó khăn gặp phải là người bệnh có thể từ chối vì lo lắng về nguy cơ gặp phản ứng có hại cao hơn. Tỉ lệ này trong nghiên cứu của Séc[8] cao hơn (43,2\%). Sự khác nhau này là do nhận thức và hiểu biết của người dân liên quan đến thuốc generic tại mỗi quốc gia là khác nhau.

Ngoài ra, 44,8\% người bán lẻ trong nghiên cứu của chúng tôi cũng cho rằng khi thay thế thuốc generic thì bác sĩ sẽ không biết loại thuốc cụ thể mà người bệnh sử dụng nên không kiểm soát hoàn toàn kế hoạch điều trị. Tỉ lệ này tương tự nghiên cứu tại Cộng hoà Séc $(42,6 \%)$ [8].

Nhận thức bị ảnh hưởng bởi kiến thức và nguồn cung cấp kiến thức. Kết quả nghiên cứu của chúng tôi cho thây kiến thức về thuốc generic của người bán lẻ là chủ yếu có được từ trường đại học, cao đẳng $(62,8 \%)$. Kết quả này thấp hơn nghiên cứu được thực hiện tại Lebanon (74\%) [6]. Một nghiên cứu cũng được thực hiện trên nhóm đối tượng bao gồm dược sĩ và kỹ thuật viên dược ở nhà thuốc. Như vậy, bên cạnh việc đưa vào chương trình đào tạo về thuốc generic cho sinh viên thì cân phải có các chương trình đào tạo liên tục, cập nhật cho người đang hành nghề để họ có kiến thức và nhận thức tốt về thuốc generic.

Theo hiểu biết của chúng tôi đây là nghiên cứu đầu tiên về lợi ích và khó khăn của việc thay thế thuốc generic tai nhà thuốc trong cộng đồng. Tuy nhiên, nghiên cứu còn hạn chế trong khả năng ngoại suy do sử dụng phương pháp lấy mẫu thuận tiện để lựa chọn các nhà thuốc tham gia vào nghiên cứu.

\section{KẾT LUÂN}

Việc thay thế thuốc generic tại nhà thuốc cộng đồng mang lại lợi ích lớn nhẩt là giúp tiết kiệm chi phí cho người bệnh. Tuy nhiên việc thay thế thuốc generic cũng có khó khăn là có thể làm xuất hiên những nhà thuốc độc quyền một số thuốc. Như vậy cần có giải pháp để tiếp tục thúc đẩy phát triển thuốc generic và ngăn ngừa tình trạng độc quyền thuốc.

\section{TÀI LIỆU THAM KHẢO}

1. Bô Y tế (2018). Thông tư quy định về thực hành tốt cơ sở bán lẻ thuốc. . 
2. Thủ tướng Chính phủ (2014). Quyết định phê duyêt chiến lược quốc gia phát triến ngành Dước Việt Nam giai đoạn đên năm 2020 và tâm nhìn đến năm 2030, Quyết định số 68/2014/QĐ-TTg ban hành ngày 10/01/2014. .

3. Alkhuzaee F.S., Almalki H.M., Attar A.Y. và công sứ. (2016). Evaluating community pharmacists' perspectives and practices concerning generic medicines substitution in Saudi Arabia: A cross-sectional study. Health Policy, 120(12), 1412-1419.

4. Awaisu A., Kheir N., Ibrahim M.I.M. và công sư. (2014). Knowledge, attitudes, and practices of community pharmacists on generic medicines in Qatar. Int J Clin Pharm, 36(2), 394-404.

5. Babar Z.-U.-D., Grover P., Stewart J. và cộng sự. (2011). Evaluating pharmacists' views, knowledge, and perception regarding generic medicines in New Zealand. Res Social Adm Pharm, 7(3), 294-305.
6. El-Jardali F., Fadlallah R., Morsi R.Z. và cộng sư. (2017). Pharmacists' views and reported practices in relation to a new generic drug substitution policy in Lebanon: a mixed methods study. Implement Sci, 12(1), 23.

7. Kalisch L.M., Roughead E.E., và Gilbert A.L. (2007). Pharmaceutical brand substitution in Australia--are there multiple switches per prescription?. Aust N Z J Public Health, 31(4), 348-352.

8. Maly J., Dosedel M., Kubena A. và cộng sự. (2013). Analysis of pharmacists' opinions, attitudes and experiences with generic drugs and generic substitution in the Czech Republic. Acta Pol Pharm, 70(5), 923-931.

9. Shraim N.Y., Al Taha T.A., Qawasmeh R.F. và cộng sự. (2017). Knowledge, attitudes and practices of community pharmacists on generic medicines in Palestine: a cross-sectional study. BMC Health Serv Res, 17(1), 847.

\section{HIÊ̂U QUẢ DỰ PHÒNG BÊ̂NH NHA CHU Ở HỌC SINH 12 TUỔI TAI TİNH TIỀN GIANG}

\section{TÓM TẮT}

Đặt vấn đề: gánh nặng do bệnh răng miệng gây ra trong công đồng là không nhỏ. Nên phải quan tâm đến dự phòng bệnh răng miệng, trong đó có bệnh nha chu, dư phòng ngay tữ lứa tuổi trẻ em. Mực tiêu: đánh giá hiệu quả dự phòng bệnh nha chu ở học sinh 12 tuổi tại tỉnh Tiền Giang. Phương pháp: nghiên cứu can thiệp có đối chứng, 1.259 học sinh không sâu răng được chia thành 3 nhóm, can thiệp giáo dục sức khỏe răng miệng, súc miệng nước Colgate $®$ Plax trong 18 tháng và đánh giá kết quả sau 30 tháng. Kết quả: sau can thiệp, tỷ lệ học sinh mắc bệnh nha chu cao nhất ở nhóm chứng $(74,4 \%)$, giảm dân ở nhóm can thiệp $1(47,8 \%)$ và thấp nhất ở nhóm can thiệp 2 $(41,8 \%)$; hiệu quả can thiệp giữa nhóm can thiệp 1 và 2 so nhóm chứng tăng lần lướt là $29,4 \%$ và $38,4 \%$. Hiệu quả can thiệp giữa nhóm can thiệp 1 và 2 so với nhóm chứng về trung bình: nhu câu điêu trị nha chu cộng đồng (CPITN) tăng lần lượt là $9,5 \%$ và $93,4 \%$; mảng bám răng (DIS) tăng $544,6 \%$ và $559,9 \%$; vôi răng (CIS) giảm $41,6 \%$ và tăng $41,7 \%$; vệ sinh răng miệng (OHIS) tăng $92,8 \%$ và $119,4 \%$. Kết luân: giáo dục sức khỏe răng miệng kết hợp nước súc miệng mang lại hiệu quả dự phòng bệnh nha chu cao hớn giáo dục sức khỏe đơn thuân.

*Bệnh viện Đa khoa Trung tâm Tiền Giang

**Trường Đai hoc Y Dước Cần Thơ

Chịu trách nhiệm chính: Lê Hoàng Hạnh

Email: lehoanghanh2707@gmail.com

Ngày nhận bài: 22.01.2021

Ngày phản biên khoa hoc: 19.3.2021

Ngày duyệt bài: 29.3.2021
Lê Hoàng Hạn *, Tạ Văn Trầm*, Lê Thành Tài**, Trần Thị Phương Đan**

Tư khóa: bệnh nha chu, CPITN, DIS, CIS, OHIS, Tiền Giang.

\section{SUMMARY \\ EFFICIENCY OF PERIODONTAL DISEASE PREVENTION IN 12-YEAR-OLD STUDENTS IN TIEN GIANG PROVINCE}

Background: the burden caused by oral diseases in the community is not small. So it is necessary to pay attention to the prevention of oral diseases, including periodontal disease, prevention right from the age of children. Objective: in order to evaluate the effectiveness of periodontal disease prevention among 12-year-old students in Tien Giang province. Methods: using controlled intervention study, 1,259 students who have no tooth decay divided into 3 groups, oral health education intervention, Colgate $\AA$ Plax mouthwash for 18 months and evaluation of results after 30 months. Results: after the intervention, the rate of students with periodontal disease was highest in the control group (74.4\%), gradually decreased in the intervention group 1 $(47.8 \%)$ and lowest in the intervention group 2 $(41,8 \%)$; effectiveness of intervention between the intervention group 1 and 2 compared with the control group increased by $29.4 \%$ and $38.4 \%$ respectively. The intervention efficiency between the intervention group 1 and 2 compared with the control group on average Community Periodental index of treatment needs (CPITN) increased by $9.5 \%$ and $93.4 \%$ respectively; Debris index simplified (DIS) increased $544.6 \%$ and $559.9 \%$; Calculus index simplified (CIS) decreased $41.6 \%$ and increased $41.7 \%$; Oral Hygiene index simplified (OHIS) increased $92.8 \%$ and $119.4 \%$. 